\title{
An Overview of Research Activities on Materials for Nuclear Applications at the INL Safety, Tritium, and Applied Research Facility
}

\author{
International Conference on Fusion Reactor Materials
}
P. Calderoni
J. Sharpe
M. Shimada
B. Denny
B. Pawelko
S. Schuetz
G. Longhurst
Y. Hatano
M. Hara
Y. Oya
T. Otsuka
K. Katayama
S. Konishi
K. Noborio
Y. Yamamoto

The INL is a

U.S. Department of Energy

National Laboratory

operated by

Battelle Energy Alliance

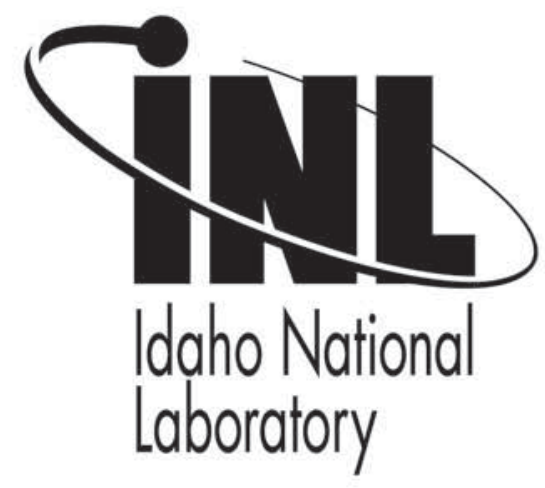

\section{September 2009}

This is a preprint of a paper intended for publication in a journal or proceedings. Since changes may be made before publication, this preprint should not be cited or reproduced without permission of the author. This document was prepared as an account of work sponsored by an agency of the United States Government. Neither the United States Government nor any agency thereof, or any of their employees, makes any warranty, expressed or implied, or assumes any legal liability or responsibility for any third party's use, or the results of such use, of any information, apparatus, product or process disclosed in this report, or represents that its use by such third party would not infringe privately owned rights. The views expressed in this paper are not necessarily those of the United States Government or the sponsoring agency. 
[00485]

An overview of research activities on materials for nuclear applications at the INL

\section{Safety, Tritium and Applied Research facility}

P. Calderoni ${ }^{1}$, J. Sharpe ${ }^{1}$, M. Shimada ${ }^{1}$, B. Denny ${ }^{1}$, B. Pawelko ${ }^{1}$, S. Schuetz ${ }^{1}$, G. Longhurst ${ }^{1}$, Y. Hatano ${ }^{2}$,

M. Hara ${ }^{2}$, Y. Oya ${ }^{3}$, T. Otsuka ${ }^{4}$, K. Katayama ${ }^{4}$, S. Konishi ${ }^{5}$, K. Noborio ${ }^{5}$, Y. Yamamoto ${ }^{5}$

${ }^{1}$ Fusion Safety Program, Idaho National Laboratory, PO Box 1625, Idaho Falls, ID 83415-7113 USA

${ }^{2}$ Hydrogen Isotope Research Center, University of Toyama, Gofuku 3190, Toyama 930-8555, Japan

${ }^{3}$ Radioscience Research Laboratory, Faculty of Science, Shizuoka University, 836 Ohya, Suruga-ku, Shizuoka 422-8529, Japan

${ }^{4}$ Interdisciplinary Graduate School of Engineering Sciences, Kyushu University, 6-10-1 Hakozaki,

Higashi-ku, Fukuoka 812-8581, Japan

${ }^{5}$ Institute of Advanced Energy, Kyoto University, Gokasho, Uji, Kyoto 611-0011, Japan

Corresponding Author

$\begin{array}{ll}\text { Name } & : \text { Pattrick Calderoni } \\ \text { Postal address } & : \text { PO Box 1625, Idaho Falls, ID 83415-7113 USA } \\ \text { Telephone number } & :+1-208-533-4547 \\ \text { Fax number } & :+1-208-533-4207 \\ \text { E-mail address } & : \text { Pattrick.Calderoni@inl.gov }\end{array}$

*Manuscript with a cover page is saved as a file name : 00485_Calderoni_manuscript_Rev1 .doc 
An overview of research activities on materials for nuclear applications at the INL

\section{Safety, Tritium and Applied Research facility}

$\underline{\text { P. Calderoni }^{1}}$ J. Sharpe $^{1}$, M. Shimada ${ }^{1}$, B. Denny ${ }^{1}$, B. Pawelko ${ }^{1}$, S. Schuetz ${ }^{1}$, G. Longhurst ${ }^{1}$, Y. Hatano $^{2}$, M. Hara ${ }^{2}$, Y. Oya ${ }^{3}$, T. Otsuka ${ }^{4}$, K. Katayama ${ }^{4}$, S. Konishi ${ }^{5}$, K. Noborio ${ }^{5}$, Y. Yamamoto $^{5}$

${ }^{1}$ Fusion Safety Program, Idaho National Laboratory, PO Box 1625, Idaho Falls, ID 834157113 USA

${ }^{2}$ Hydrogen Isotope Research Center, University of Toyama, Gofuku 3190, Toyama 9308555, Japan

${ }^{3}$ Radioscience Research Laboratory, Faculty of Science, Shizuoka University, 836 Ohya, Suruga-ku, Shizuoka 422-8529, Japan

${ }^{4}$ Interdisciplinary Graduate School of Engineering Sciences, Kyushu University, 6-10-1 Hakozaki, Higashi-ku, Fukuoka 812-8581, Japan

${ }^{5}$ Institute of Advanced Energy, Kyoto University, Gokasho, Uji, Kyoto 611-0011, Japan

Abstract

The Safety, Tritium and Applied Research facility at the Idaho National Laboratory is a US Department of Energy National User Facility engaged in various aspects of materials research for nuclear applications related to fusion and advanced fission systems. Research activities are mainly focused on the interaction of tritium with materials, in particular plasma facing components, liquid breeders, high temperature coolants, fuel cladding, cooling and blanket structures and heat exchangers. Other activities include validation and verification experiments in support of the Fusion Safety Program, such as beryllium dust reactivity and dust transport in vacuum vessels, and support of Advanced Test Reactor irradiation experiments. This paper presents an overview of the programs engaged in the activities, which include the US-Japan TITAN collaboration, the US ITER program, the Next Generation Power Plant program and the tritium production program, and a presentation of ongoing experiments as well as a summary of recent results with emphasis on fusion relevant materials.

Keywords:(Provide a maximum of 6 keywords)

tritium, fusion, blanket, ITER, VHTR, NGNP 


\section{Introduction}

The Safety and Tritium Applied Research facility at the Idaho National Laboratory is a US Department of Energy (DOE) National User Facility that provides laboratory infrastructure to study tritium science and technology issues associated with the development of efficient, safe and environmentally friendly nuclear energy systems [1-4]. STAR became operational with tritium in January 2006 and since then the laboratory main research thrust lies within the activities of the INL Fusion Safety Program in support of the US ITER Project as well as other national and international collaborative programs for the development of magnetic and inertial fusion energy systems [5,6]. Experimental activities related to the US-Japan TITAN collaborative program, which started in 2007 , are of particular relevance to fusion materials science and will be presented in detail. In addition, STAR provides support to other research programs related to advanced nuclear power plants, in particular for the Very High Temperature Reactor (VHTR) program and the related Next Generation Nuclear Plant (NGNP), as well as support of irradiation experiments in the INL Advanced Test Reactor (ATR) related to tritium generation.

STAR is classified as a Radiological, Low Hazard Facility, and it is restricted to a facility total tritium inventory of less than 16,000 Ci, the threshold limit for a DOE Category-3 Nuclear Facility [7]. To assure compliance with this limit, the tritium inventory is administratively controlled to $15,000 \mathrm{Ci}$, while tritium is received on a need basis in 1,000 $\mathrm{Ci}$ aliquots using Type A shipping containers.. The STAR facility exists within a multi-room complex in two adjoining buildings located at the INL Advanced Test Reactor Complex. The facility provides about $400 \mathrm{~m}^{2}$ of working area for bench scale experiments and limited engineering scale tests utilizing conventional laboratory infrastructure (power, water, pressurized air, HVAC, controlled ventilation hoods, and inert-gas gloveboxes) and tritium handling infrastructure. The combined capability of handling tritium and radioactive materials, as well as other controlled chemical elements such as beryllium and lead, provides unique opportunities for the experimental investigation of synergistic phenomena that involve hydrogen isotopes and neutron irradiation on many components of fusion experimental devices and other nuclear energy systems.

This paper summarizes recent and ongoing research activities in STAR with direct or indirect relevance to fusion energy systems materials. These can be grouped under the following broad categories:

- Plasma Facing Component (PFC) materials

- Liquid breeders and coolants 
- $\quad$ Fuel cladding

- Heat Exchanger (HX) structural materials

\section{Tritium retention in PFC materials}

Tritium retention inside the vacuum vessels is an important issue for the effective and safe operation of current and planned fusion experimental devices, such as ITER, and for the design of fusion energy systems. Despite the large body of work that exists for hydrogen and deuterium retention in fusion materials, there is generally a wide disparity between results obtained in different laboratory settings with materials prepared in different ways and a consequent unacceptable uncertainty in the prediction of invessel inventories that motivates the experimental activities in STAR in this area. In addition, the use of tritium improves the sensitivity of the retention measurement significantly, enhancing the detection limit up to parts per billion, while the capability of handling radioactive materials in STAR allows the investigation of the synergistic effect of neutron irradiation on tritium retention. As an example of enhanced tritium diagnostics, Fig.1 shows preliminary results of the use of the Imaging Plate (IP) methodology for depth profiling of tritium retention in PFC materials. The Imaging Plate is a film-like radiation image sensor developed by Fujifilm, Co., comprised of specifically designed phosphors that trap and store the tritium radiation energy. The stored energy is stable until scanned with a laser beam, which releases the energy as luminescence in a process defined as "photostimulated luminescence" (PSL). The processed image returned by the instrument is a two dimensional map of the tritium concentration over the scanned surface. To check depth profiling feasibility, split samples $(6 \mathrm{~mm}$ diameter, $10 \mathrm{~mm}$ long cylinders cut in half across the length) of tungsten, molybdenum, low activation ferritic steel (F82H) and stainless steel 316. have been prepared and exposed to a mixture of tritium/deuterium plasma $\left(0.2 \% \mathrm{~T}_{2} \mathrm{D}_{z}\right)$ have been tested in TPE and then analyzed by Imaging Plate. The samples have been polished to mirror finish before plasma exposure. The front surface of split samples were exposed to $0.2 \%$ tritium/deuterium mixture plasmas with fluences of $0.5 \times 10^{25} \mathrm{~m}^{-2}$ and at fluxes of about $5.0 \times 10^{21} \mathrm{~m}^{-2} \mathrm{~s}^{-1}$. The ion energy onto the sample surface was $70 \mathrm{eV}$ corresponding to an implantation depth of about $2.3 \mathrm{~nm}$. Fig.1 shows the tritium accumulation on the cross sectional surface of a sample of polycristalline tungsten provided by Allied Material Co, pre-annealed at $873 \mathrm{~K}$ and polished after exposure. The cross sectional surfaces were polished again with 1200 grit paper after TPE exposure and before the Imaging Plate measurement to
Formatted: Tab stops: Not at $1.17 "+2.33^{\prime \prime}+3.5^{\prime \prime}+4.67 "$

Formatted: Superscript
Formatted: Superscript
Formatted: Superscript
Formatted: Superscript
Formatted: Superscript


remove the contribution of tritium from the surfaces, in order to focus on depth profiling. The contribution of tritium reaching the Imaging Plate through air from the non polished surfaces is evident in Fig 1 as a high counting contour surrounding the samples. Because of the low-energy of tritium beta emission this external contribution does not influence depth profiling analysis. Although these are preliminary results of an experimental campaign that will continue under the TITAN collaborative program, they testify the potential of tritium as a tracer element for hydrogen isotopes retention investigation.

PFC materials retention tests in STAR are carried out in the Tritium Plasma Experiment (TPE). The refurbishment of a second facility, the Tritium Ion Implantation Experiment (TRIIX), is almost completed but details are not included in this paper since the ion beam parameters have not been adequately characterized after replacing the ion source. The Tritium Plasma Experiment (TPE) is a unique linear column plasma device that uses both fusion fuels of deuterium and tritium, and has been relocated from the Tritium System Test Assembly (TSTA) at Los Alamos National Laboratory (LANL) to the STAR facility. TPE is suitable for materials exposures in plasma conditions approaching those of plasma facing components in ITER. Recent characterization of the plasma column after the experiment refurbishment was performed with a plunging Langmuir probe for target current density and a spectrometer for indication of potential impurities [8]. For typical operating conditions, the electron density ranged between $10^{16}$ and $10^{18} \mathrm{~m}^{-3}$, the electron temperature between 7 and $15 \mathrm{eV}$ and the ion flux between $10^{20}$ and $10^{22} \mathrm{~m}^{-2} \mathrm{~s}^{-1}$ in steady state. The incident beam is assumed to be primarily $\mathrm{D}+$, based on prior work with similar instruments such as PISCES-A [9].

An ex situ dual thermal desorption spectroscopy system is configured to measure H-isotope retention in exposed samples operating either in vacuum conditions to measure hydrogen and deuterium Formatted: Indent: First line: $0.56 "$ " Tab stops: Not at $1.17 "$ $+2.33^{\prime \prime}+3.5^{\prime \prime}+4.67 "$ with mass spectrometry, or with an inert gas purge to measure tritium with a beta particle counter. This separate system is located outside of the TPE glovebox and requires sample transfer in air from the TPE chamber to the desorption system chamber. Fig.2 shows an example of recent deuterium retention results obtained from exposure to TPE plasma of polycrystalline tungsten samples from Plansee pre-annealed at $1273 \mathrm{~K}$ [10]. Retention is plotted as a function of incident ion fluence at a constant sample temperature of $623 \mathrm{~K}$ (solid circles); and it shows good agreement with lower ion fluence results obtained in TPE during its tenure at LANE with the same material (empty circles). Although the ion energies of two experiments were different $(70 \mathrm{eV}$ and $100 \mathrm{eV})$, the increasing trend from the lower fluence data $[11,12]$ match the 
deuterium retention region of the higher fluence data recently measured. The saturation of deuterium retention was also observed above the incident fluence of $10^{26} \mathrm{~m}^{-2}$, althought the responsible mechanism is still under investigation. Add $[11,12]$.

\section{Tritium extraction from liquid breeder materials}

In a fusion energy system tritium is generated by neutron capture in the blanket's breeder material, extracted and re-circulated as fuel in the plasma. When the breeder is designed to operate in the liquid phase, the interaction of tritium with the lithium bearing material is one of the most important physical processes in determining the feasibility and the attractiveness of the system because it is fundamentally linked with all aspects of plant operation, from fueling (tritium breeding ratio, tritium availability, etc) to power extraction (heat transfer capability, heat cycle efficiency, etc) to safety (tritium inventory, tritium release, etc). Since the blanket operates in steady-state conditions, the accurate determination of the tritium solubility, defined as the function linking the concentration of dissolved tritium with its corresponding partial pressure at equilibrium over the liquid surface, is a fundamental design data need for all systems (magnetic or inertial confinement, hybrid systems, etc) based on liquid breeders. The other main transport properties, the diffusion constant and the mass transport coefficient at liquid and structures interfaces, play a major role in the selection and optimization of the tritium extraction and coolant purification system (in dual function blankets the two systems are acting on different fluids).

The INL Fusion Safety Program began the experimental investigation of liquid breeders properties in STAR within the framework of the second Japan/US Program on Irradiation Test for Fusion Research (JUPITER-II), which began in 2001 [6]. The material investigated was the lithium fluoride (LiF) and beryllium difluoride $\left(\mathrm{BeF}_{2}\right)$ eutectic salt, usually referred to as flibe, which has a reference composition of $2 \mathrm{LiF}+1 \mathrm{BeF}_{2}$ moles. The research focused at first on the control of structural materials corrosion by metallic beryllium [13], and then investigated tritium transport properties in the salt in static permeation tests [14]. From 2008 the focus moved from the fluoride salt to the metallic Lead Lithium Eutectic (LLE, or sometimes referred to as $\mathrm{PbLi}$ ) as the breeder material of the main blanket system under consideration in the US, as well as the material chosen for most of the ITER Test Blanket Modules proposed by other international parties [15]. The initial objective of the experiments currently ongoing in STAR is the measurement of hydrogen isotopes solubility in LLE in a static configuration. The experimental set-up allows for both
Formatted: Superscript

Formatted: Superscript

Formatted: Font: $10.5 \mathrm{pt}$

Formatted: Indent: First line:

$0.56^{\prime \prime}$ 
adsorption and desorption measurements, since the two techniques have led to systematically different results in previous studies [16]. Fig.3 summarizes the first results obtained with hydrogen at input pressure above the liquid surface ranging from $10 \mathrm{~Pa}$ to $100 \mathrm{kPa}$ and LLE temperature ranging between $300 \mathrm{C}$ and $650 \mathrm{C}$ and using the desorption method. The dotted lines are the exponential fits proposed by F. Reiter and A. Aiello and used here to summarize the extremes of the wide range of results reported in the literature $[17,18]$. Measurements are based on the PVT method, using three capacitance manometers with different ranges of sensitivity (full scale ranging from $133 \mathrm{kPa}$ to $2.6 \mathrm{~Pa}$ ) and aided by mass spectroscopy. The LLE material is supplied by Atlantic Metals Co., and has a nominal composition of $15 \% \mathrm{Li}$ in moles (Pb-15Li). Eutectic composition and impurities concentration was measured by ICP-AES and ICP-MS analysis of batch samples. Solubility tests with hydrogen are continuing to explore the effect of various parameters on the results accuracy, including the measurement method (adsorption, desorption, permeation), the liquid metal mass/volume ratio, the gas/liquid interface size and condition and other test procedure parameters such as equilibration time and desorption steps period. The experiments has been re-assembled inside a tritium glovebox and tritium solubility test will follow, allowing to expand the measurement sensitivity range in the low partial pressure with the use of beta detection counters. Detailed analysis of the results and their implication for the design and operation of ITER TBM modules and fusion blankets in general will be reported after experiments completion.

\section{Tritium behavior in TPBARs materials}

The TMIST experiments are neutron irradiation tests performed at the INL Advanced Test Reactor to investigate the effect of the radiation environment on specific components of the Tritium Producing Burnable Absorber Rods (TPBARs) used for tritium production in the Watts Bar Reactor [19]. TMIST-1 was conducted to determine whether the radiation environment caused a change in the rate at which zirconium getters would oxidize in the presence of water vapor. In this experiment, $\mathrm{D}_{2} \mathrm{O}$ was carried to the reactor core in two separate lines and at two different concentrations. The basic concept is that dry ultra-high purity helium is passed through a $\mathrm{D}_{2} \mathrm{O}$ bubbler where it becomes saturated with the water vapor. This flow is mixed with dry gas in a system of 4 mass flow controllers to provide two separate input streams to the experiment. On line data included a mass spectrometer that examined the $\mathrm{D}_{2} \mathrm{O}$ content in each of 4 separate gas streams (inlet and outlet on 2 different concentrations) and temperature and pressure 
measurements used in automatically controlling the flow through the mass flow controllers. The experiment was conducted over three reactor cycles ending in December 2008. Post irradiation examination on the test specimens is in progress to determine details of oxidation and hydriding performance. Prior to being installed in the reactor, the control system for $\mathrm{D}_{2} \mathrm{O}$ partial pressure maintenance was assembled and demonstrated at the STAR facility. Also, bench-scale tests examining the uptake and transport of water and hydrogenic species in long heated tubes were performed to assist in the design of TMIST experiments.

TMIST-2 is designed to measure the effects of neutron irradiation on the permeation characteristics of certain components of TPBAR cladding (Fig.4). Tritium is supplied to the experiment capsules containing the components at one of three different partial pressures in He carrier gas to one side of the component. Tritium permeating through the component is scavenged by a He-Ne gas mixture used for temperature control in the irradiation capsules. It is then carried to ion chamber detectors and bubbler collectors where measurements are made of the activity and thus of the permeation rate. The supply bottles of the $\mathrm{T}_{2}$-He mix used in the experiment were custom filled in the STAR facility. Concentrations of $3.77 \mathrm{e}^{-}$ $04,3.77 \mathrm{e}^{-05}$, and $8.26 \mathrm{e}^{-07} \mathrm{~T}_{2}$ in research grade He were prepared at pressures up to $1.58 \mathrm{MPa}$ in standard size-K bottles that had been previously evacuated and conditioned. Additional tests were performed in STAR to verify catalytic oxidizer lifetime for the bubblers in TMIST-2. The TMIST-2 experiment is installed in the ATR 1B Cubicle and experiment irradiation testing is presently approximately $50 \%$ complete. Bubbler vials used to collect the tritium from the various gas streams are sent to the STAR facility for disposal after the water in them has been scintillation counted.

\section{Tritium permeation through Heat Exchanger materials}

In 2002, the US Department of Energy initiated the development of a plan for an advanced gas reactor (AGR) fuel development and qualification program for coated-particle fuel to support the licensing and operation of very high temperature reactor (VHTR) systems as the nearest-term hydrogen production system among those identified in the Generation IV Nuclear Energy Systems Roadmap (Gen-IV) [20,21]. In 2005 the VHTR was chosen for the Next Generation Nuclear Plant (NGNP) Project and the fuel development and qualification program expanded and updated [22]. Part of the expansion is the inclusion of a task aimed at the characterization of fission product transport in the NGNP system, and within the task 
is the investigation of the migration of tritium from the primary coolant through the intermediate heat exchanger (IHX) and hydrogen or other chemical process heat exchangers, which would result in contamination of the final products [23]. In 2008 the NGNP project started the design and construction of an experimental facility at the STAR laboratory aimed at characterizing hydrogen and tritium permeation through candidate IHX alloys, in particular the alloy 617, 800H and Haynes 230. The Tritium Heat Exchanger materials experiment (THX) is designed to test tubular samples of the alloys at temperatures ranging from 600 to $950 \mathrm{C}$ in conditions that are relevant to NGNP IHX operation. The experiment is based on two helium loops operating at pressures ranging from atmosphere to $200 \mathrm{kPa}$ and flow rates between 0-10 liters per minute which interact in a counter-flow arrangement in the test section containing the material under investigation-(Fig.5). The primary loop helium gas contains low concentration hydrogen isotopes gas and controlled amounts of impurities (methane and water) to control the metal surface condition, and flows in the inner diameter of the tubular samples. The secondary loop contains pure helium gas and flows on the outer diameter of the samples within a concentric quartz tube, and collects and measures the tritium gas permeating through the high temperature sample material. Gas composition is monitored with a closed ion source mass spectrometer system commercialized by Inficon called Compact Process Monitor, designed to sample gas from near atmospheric process streams. Ongoing hydrogen tests are performed with hydrogen partial pressure in the primary helium ranging between $1 \%$ and $10 \underline{0} \mathrm{ppm}$. The lower limit is dictated by the sensitivity of the mass spectrometer. In the case of tritium the lower limit is dictated by background retention in the system and a two orders of magnitude increase in the range (down to 100ppb) is expected. Moisture and methane impurities are controlled to maintain a stable oxide layer on the metals surface, as expected for NGNP IHX operation [24,25]. The induction heater allows nearly instantaneous heating of the tubular samples up to $950 \mathrm{C}$ once equilibrium conditions are established in the loop gases composition. Furthermore, the low thermal inertia of the system allows the investigation of the effect of thermal cycling and aging on tritium permeation due to variation of the alloys microstructure. THX uses a stainless steel glove-box for secondary containment of tritium from all components subject to high temperatures or directly connected to the high flow primary and secondary loops, including the circulation pumps. Measured hydrogen permeability data for the alloy $800 \mathrm{H}$ are shown in Fig. 5 with comparison to available references. 


\section{Summary}

The Safety, Tritium and Applied Research facility at the Idaho National Laboratory is a US Department of Energy National User Facility engaged in various aspects of materials research for nuclear applications related to fusion and advanced fission systems, with focus on the characterization of the behavior of hydrogen isotopes in nuclear technology components. This paper reported on the status of ongoing experimental activities in STAR funded by the US Department of Energy and relevant to fusion reactor materials.

\section{References}

(1) R.A. Anderl, D.A. Petti, K.A. McCarthy, G.R. Longhurst, Fusion Sci. Technol. 41 (2002) 568-572.

(2) R. A. Anderl, et al, Fusion Sci. Technol. 48 (2005) 243-249.

(3) G. R. Longhurst, R. A. Anderl,, R. J. Pawelko, C. J. Stoots, Fusion Sci. Technol. 48 (2005) 332-336.

(4) R. J. Pawelko, J. P. Sharpe, B. J. Denny, Fusion Sci. Technol. 54 (2008) 157-159.

(5) D. A. Petti, S. Reyes, L. C. Cadwallader, J. F. Latkowski, Fusion Sci. Technol., 47 (2005) 949-958.

(6) D. A. Petti, et al, Fusion Eng. Des. 81 (2006) 1439-1449.

(7) Hazard Categorization and Accident Analysis Techniques for Compliance with DOE Order 5480.23, Nuclear Safety Analysis Reports, DOE-STD-1027-92 (1992).

(8) R D Kolasinski, et al, Phys. Scr. T138 (2009) 1-5 M. Shimada, R. D. Kolasinski, J.P. Sharpe, R.A.4- - - Formatted: Bullets and Causey, Rev. Sei. Instrum (2009) In press

$(8)$.

(9)-E.M. Hollman, Y.A. Pigarov, Phys. Plasmas 9 (10) (2002) 4330.

(10) J. P. Sharpe, R. D. Kolasinski, M. Shimada, R. A. Causey, J. Nucl. Mater. 390-391 (2009) 709-712

(11) R. A. Causey, K. Wilson, T. Venhaus, W. R. Wampler, J. Nucl. Mater. 266-269 (1999) 467-471

(12) T. Venhaus, R. A. Causey, R.P. Doerner, T. Abeln, J. Nucl. Mater. 290-293 (2001) 505-508

(13) P. Calderoni, P. Sharpe, H. Nishimura, T. Terai, J. Nucl. Mater. 386-388 (2009) 1102-1106

(14) P. Calderoni, P. Sharpe, M. Hara, S. Oya, Fusion Eng. Des. 83 (2008) 1331-1334.

(15) L. Giancarli, et al, J. Nuc. Mater. 367-370(2) (2007) 1271-1280.

(16) E. Mas de les Valls, et al, J. Nuc. Mater. 376 (2008) 353-357.

(17) F. Reiter, Fus. Eng. Des. 14 (1991) 207-211 
(18) A. Aiello, A. Ciampichetti, G. Benamati, Fus. Eng. Des. 81 (2006) 639-644

(19) G. R. Longhurst, TMIST-2 Transport Test, INL/EXT-08-13791 (2008)

(20) Technical Program Plan for the Advanced Gas Reactor Fuel Development and Qualification Program, ORNL/TM-2002/262 (2003).

(21) A Technology Roadmap for Generation IV Nuclear Energy Systems, U.S. DOE Nuclear Energy Research Advisory Committee and the Generation IV International Forum, GIF-002-00 (2002).

(22) Technical Program Plan for the Advanced Gas Reactor Fuel Development and Qualification Program, Rev. 1, INL/EXT-05-00465 (2005).

(23) D. L. Hanson, Test Plan for Characterizing Tritium Transport in a VHTR, General Atomics, PC000550, Rev. 0 (2007)

(24) S.K. Sharma, G.D. Ko, F.X. Li, K.J. Kang, J. Nuc. Mater. 378 (2008) 144-152

(25) R. Wright, Proc. 4th International Topical Meeting on High Temperature Reactor Technology, 2

(2008) 75-79

(26) A.S. Schmidt, F. Verfuss, E. Wicke, Journal of Nuclear Materials 131 (1985) 247-260. 
Figure captions

Fig.1: Imaging Plate scan of the cross section of a split tungsten sample exposed to tritium plasma in TPE.

Fig.2: Deuterium retention in PLANSEE polycrystalline tungsten as a function of incident ion fluence.

Fig.3: Hydrogen solubility in Lead Lithium Eutectic.

Fig.4: TMIST 2 configuration.

Fig.5: Hydrogen permeability of $800 \mathrm{H}$ alloy THX test section diagram and picture. 

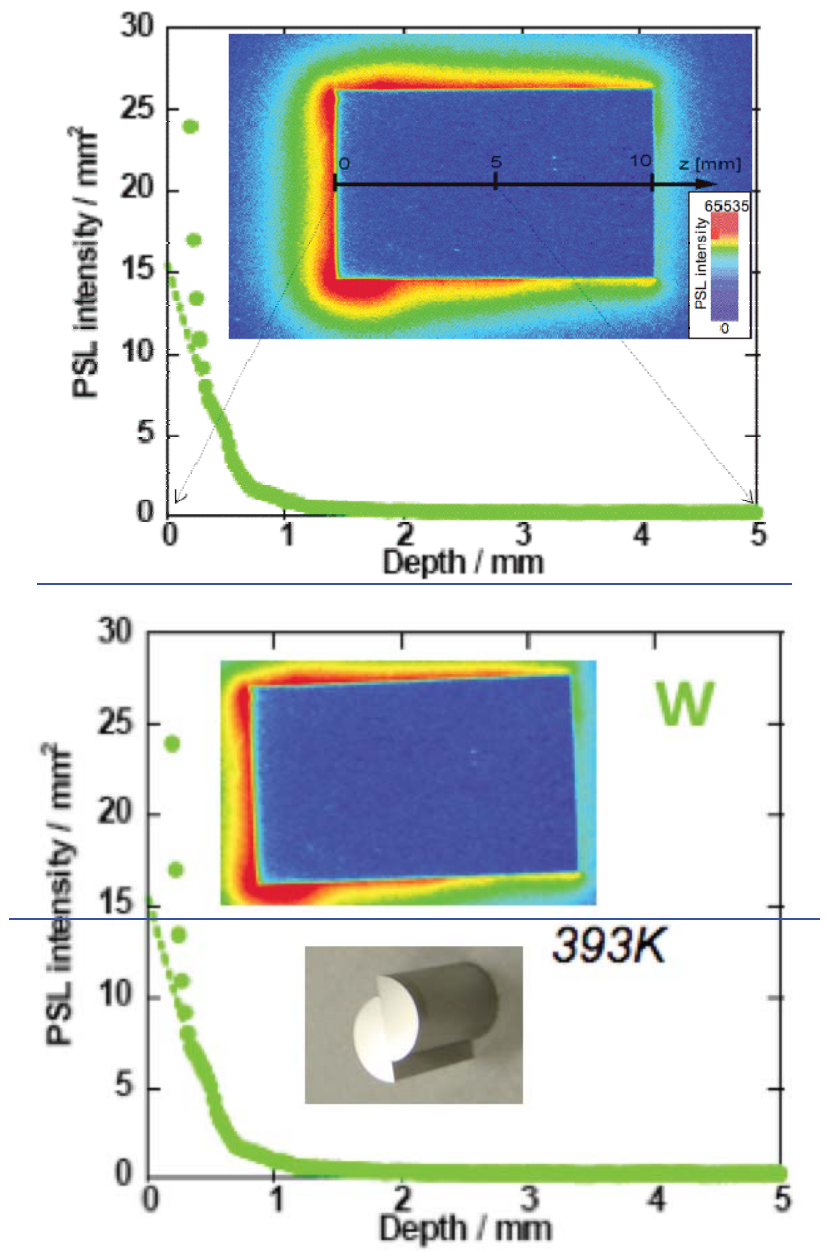

Corresponding Author name: P. Calderoni

Column width: one column 


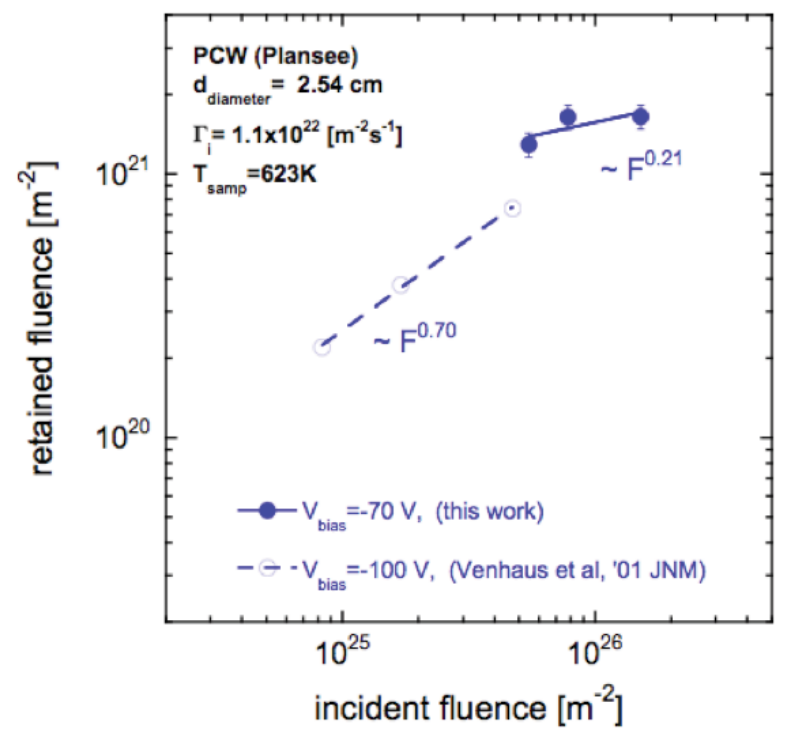

Corresponding Author name: P. Calderoni

Column width: one column 
Formatted: Font: Italic,

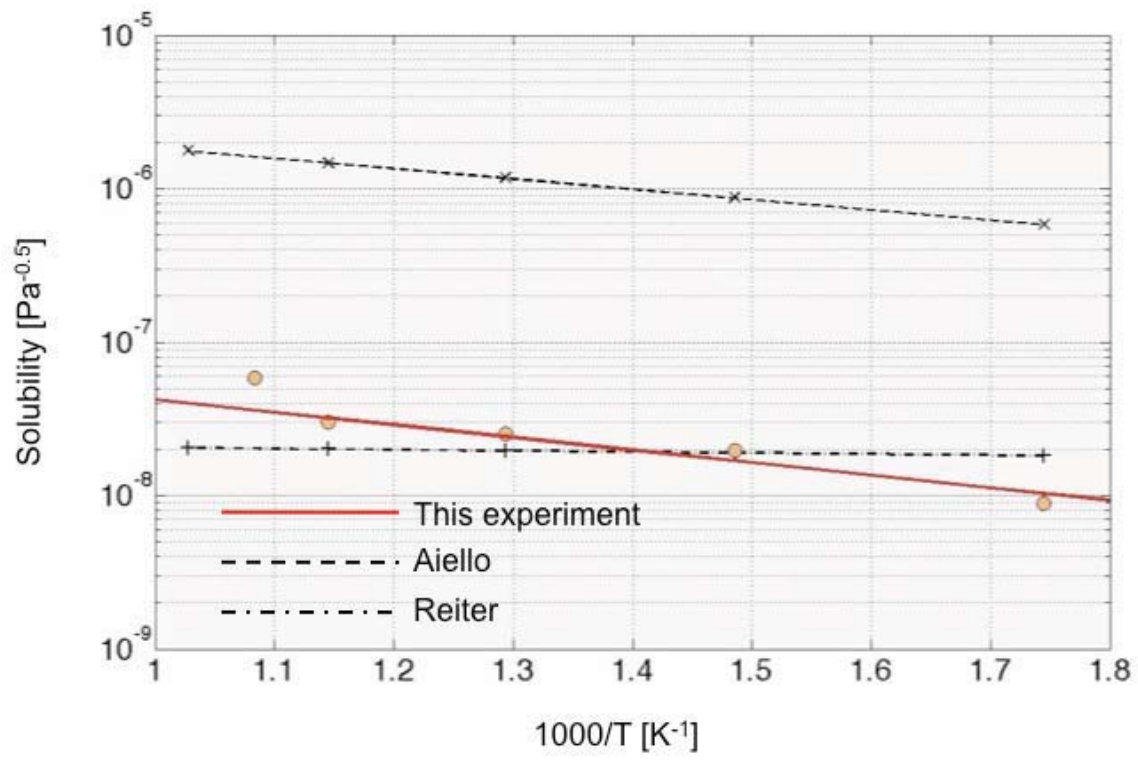

$y:$ solubility $\left[\mathrm{Pa}^{-0.5}\right]$

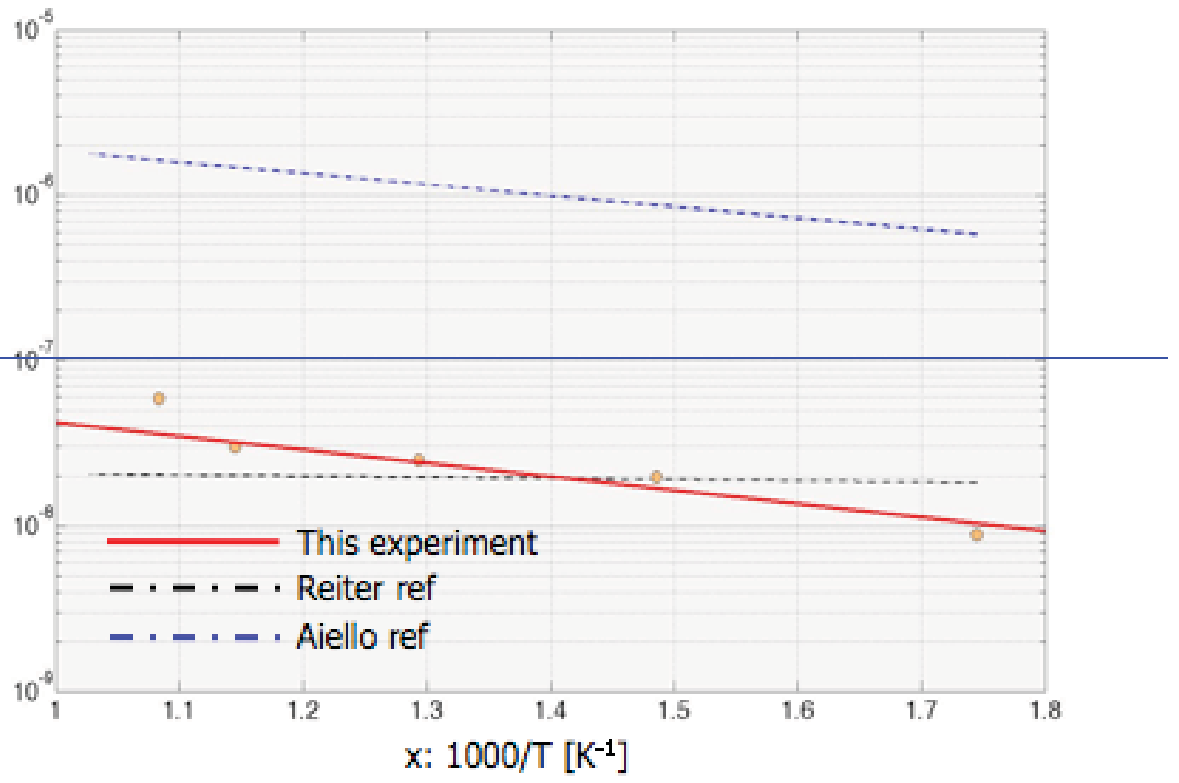


Corresponding Author name: P. Calderoni

Column width: one column 


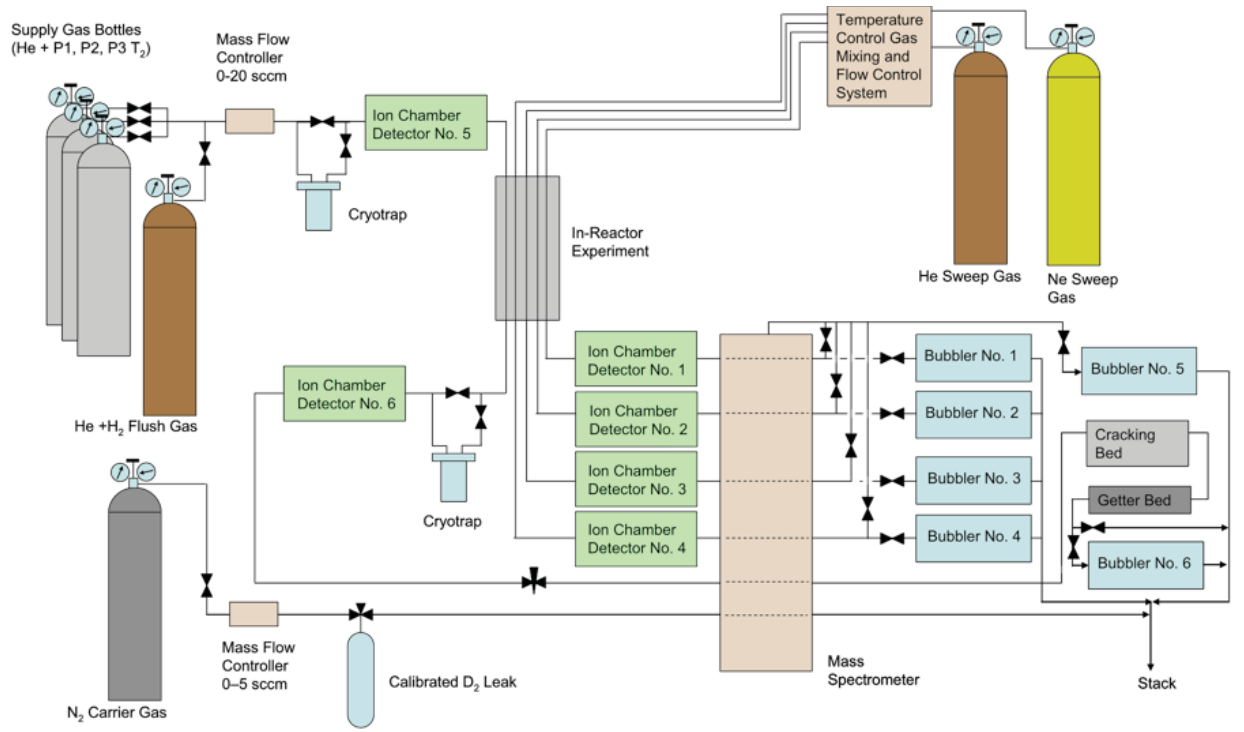

Corresponding Author name: P. Calderoni

Column width: two columns 
Formatted: Font: Italic,
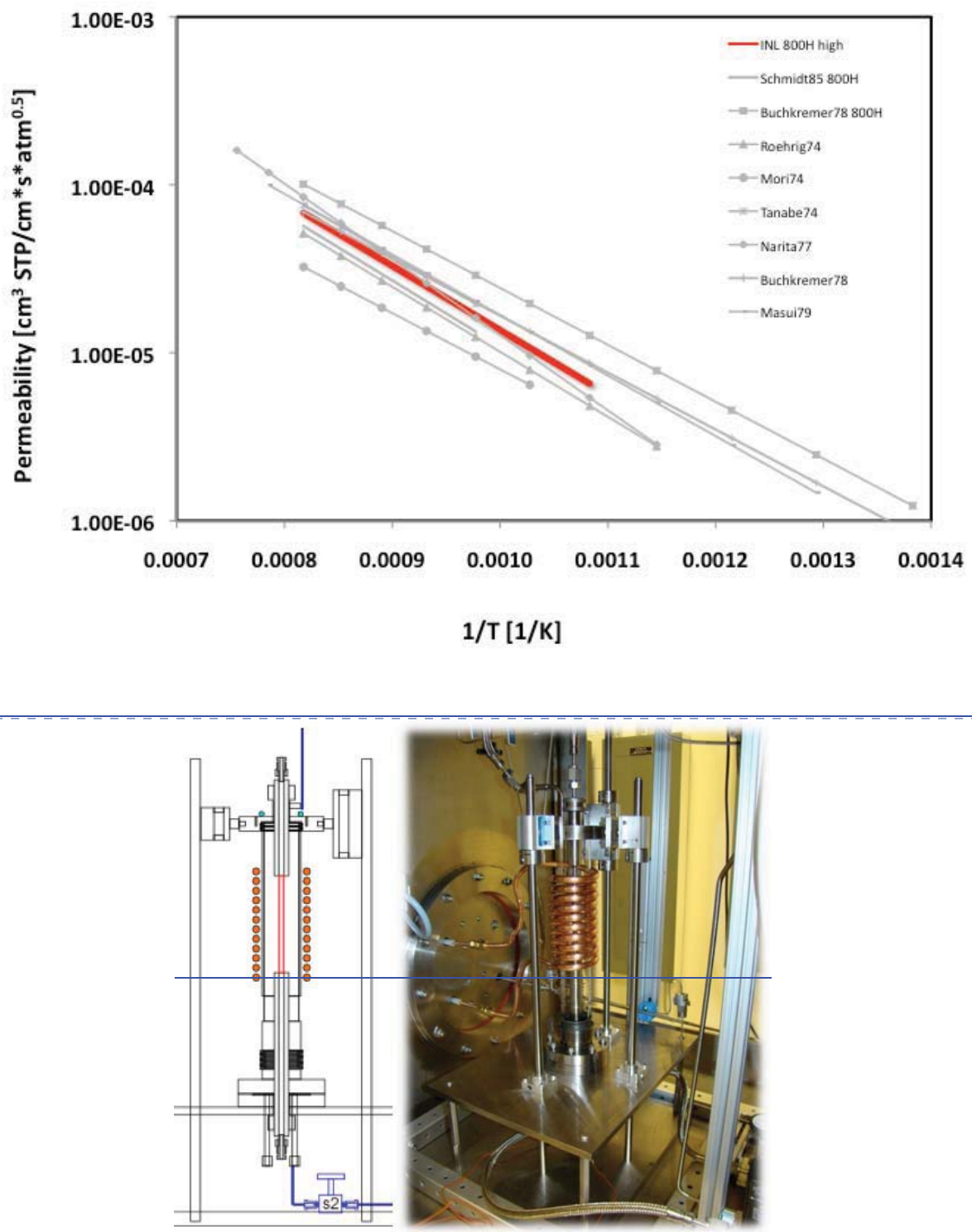

Corresponding Author name: P. Calderoni

Column width: one column 